\title{
Evaluation of the effectiveness of remineralization preparations used in paediatric dentistry practices
}

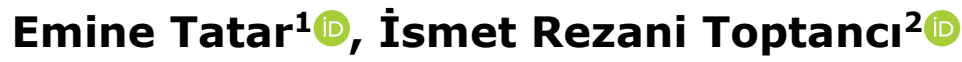 \\ ${ }^{1}$ Kahramanmaraş Sütçü İmam University, Faculty of Dentistry, Department of Paediatric Dentistry, Kahramanmaraş, Turkey. \\ ${ }^{2}$ Dicle University, Faculty of Dentistry, Department of Paediatric Dentistry, Diyarbakır, Turkey.
}

\section{Abstract}

\section{Correspondence:}

\section{Dr. Emine TATAR}

Kahramanmaraş Sütçü İmam

University, Faculty of Dentistry,

Department of Paediatric Dentistry,

Kahramanmaraş, Turkey

E-mail:dteminetatar@gmail.com

Received: 3 September 2019

Accepted: 4 December 2019

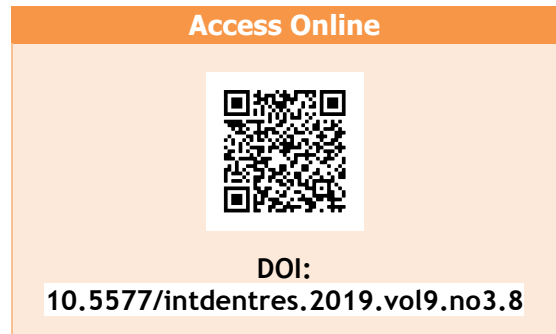

\section{Introduction}

Tooth decay is a chronic, progressive disease that is caused by fermenting carbohydrates that are created by pathogenic microorganisms in the mouth. These carbohydrates cause acid dissolution in the tooth. Nutritional regulation and oral hygiene education, as SEM, EDX
Aim: The goal of this particular research was to scrutinize the remineralization effects of fluoride varnish, casein phosphopeptide amorphous calcium phosphates (CPP-ACP) and casein phosphopeptide amorphous calcium fluoride phosphates (CPP-ACFP) cream, and tricalcium phosphate (TCP) varnish.

Methodology: The study was designed as an experimental research whereby samples with early artificial caries lesions were randomly divided into the following 5 groups with 20 samples in each group: (I) control, (II) fluoride varnish, (III) CPP-ACP cream, (IV) CPP-ACFP cream and (V) TCP varnish. The effectiveness of these remineralization agents was evaluated using a laser fluorescence device (DIAGNOdent), a scanning electron microscope (SEM) and energy dispersive X-ray analysis (EDX).

Results: In the pre- and post-treatment evaluations, the DIAGNOdent remineralization measurements were statistically significant in all the groups, except the control group $(\mathrm{p}<0.05)$. In comparison with the DIAGNOdent measurements, the CPP-ACFP group was found to have significantly higher remineralization than the fluoride group $(p<0.05)$, while no significant differences were found between the other groups ( $p>0.05$ ). The EDX analysis evaluated the $\mathrm{Ca} / \mathrm{P}$ ratio between the groups. These results indicated that the CPP-ACFP group was significantly higher than the control group, the CPP-ACP group and the TCP group $(p<0.05)$; no significant differences were found between the CPP-ACFP group and the fluoride group $(p>0.05)$. In SEM imaging, the most extensive mineral accumulation was observed in the CPP-ACFP group.

Conclusions: Three analytical methods demonstrated that CPP-ACFP was the most effective remineralization material tested in this study.

Keywords: Fluoride varnish, CPP-ACP, CPP-ACFP, TCP, DIAGNOdent,

How to cite this article: Tatar E, Toptanc İR. Evaluation of the effectiveness of remineralization preparations used in paediatric dentistry practices. Int Dent Res 2019;9(3):138-44. well as physician-applied protective agents, are crucial to prevent tooth decay, especially in children.

Fluoride is the most common caries prevention agent used in dentistry. Fluoride glycolysis suppresses and reduces the production of extracellular polysaccharides, minimises the carcinogenic potential of Streptococcus mutans and, at high concentrations, has a bactericidal effect (1). Fluoride varnish has been 
used in preventive community-based programs in children and adults who are at a high risk of caries.

Milk contains particles of casein that have a diameter of $30-300 \mathrm{~nm}$. This phosphoprotein constitutes approximately $80 \%$ of milk's total protein structure (2). Casein phosphopeptide (CPP), a protective factor found in milk and dairy products, is obtained by disintegrating casein using a selective precipitation method (3). When casein phosphopeptide amorphous calcium phosphate (CPP-ACP) is applied to white spot lesions, calcium and phosphate ions are rapidly released to remineralise the partially demineralised enamel crystals (4).

CPP-ACP and fluoride can have a synergistic effect in the prevention of caries formation. A study conducted by Reynolds et al. (1998) revealed that when a $500 \mathrm{mg}$ solution containing fluoride and a $1 \%$ solution containing CPP-ACP were used together, the remineralization effect was increased, and $50 \%$ of the fluoride was bound to the CPP-ACP. The researchers described this newly formed product as casein phosphopeptide amorphous calcium fluorophosphate (CPP-ACFP) (5).

Tricalcium phosphate

(TCP) affects remineralization by increasing the calcium levels in the dental plaque and saliva. TCP dissolves when it contacts a tooth surface that has been moistened with saliva, releasing calcium, phosphate and fluoride ions. Subsequently, the calcium and fluoride ions react on the weak enamel surface to form a nucleus, facilitating mineral growth (6).

Modern studies on prospective caries detection require the measurement of minute changes in the mineral content of a tooth, particularly when assessing single caries lesion. Microanalytic techniques used to estimate the quantity of minerals in a given tooth sample include EDX or EDS and $\operatorname{SEM}(7,8,9)$.

In an in vitro study by Pai et al. (2008), DIAGNOdent and SEM were used to evaluate the remineralization effect of CPP-ACP on initial enamel caries. The DIAGNOdent data yielded significant remineralization results after treatment, and SEM images of the remineralised areas supported the DIAGNOdent findings (10). Jayarajan et al, also used DIAGNOdent and SEM to investigate the remineralization of CPP-ACP and CPP-ACFP on enamel samples. The researchers reported that the highest mineral accumulation was observed in the CPP-ACFP group, followed by the CPP-ACP and control groups, based on SEM images (11). A similar study by Bhat et al. (2012) used DIAGNOdent and SEM to investigate the remineralization of CPP-ACP and CPP-ACFP on enamel. SEM images showed that the highest mineral accumulation occurred in the CPP-ACFP group, followed by the CPP-ACP and control groups (12).

Patil et al. (2013) also examined the remineralization effects of CPP-ACP, CPP-ACFP and TCP using DIAGNOdent analysis following demineralisation and remineralization cycles. They reported a statistically significant remineralization effect in all the experimental groups except the control group; the highest degree of remineralization was measured in the TCP-F group, followed by the CPPACFP and CPP-ACP groups (13).

This study was motivated to evaluate the remineralization effects of fluoride varnish, casein phosphopeptide amorphous calcium phosphates (CPPACP) and casein phosphopeptide amorphous calcium fluoride phosphates (CPP-ACFP) cream, and tricalcium phosphate (TCP) varnish with the ultimate aim of revealing the most efficient one among them.

\section{Materials and Methods}

This study was approved by the Ethics Committee, Faculty of Dentistry, Dicle University, Turkey (Dated 23.06.2017, Meeting No. 6, Decision No. 7).

This study examined 100 anterior primary teeth with no carious lesions, macroscopically observable cracks or colouration. Any residues on the tooth surfaces were cleaned using a periodontal curette, a brush and a fine-grain polishing paste. Subsequently, the teeth were disinfected in distilled water with $0.1 \%$ thymol at $+4^{\circ} \mathrm{C}$.

The crowns of the teeth were separated from the roots using a diamond disc (NTI, Germany) under cooling water with a micromotor (NSK FX23, Japan). The teeth were randomly divided into 'five' groups as follows: control group, fluoride varnish group, CPP-ACP group, CPP-ACFP group and TCP group. Each group was allocated 20 samples. Within each group, four samples were evaluated by SEM analysis, and 10 samples were evaluated by EDX analysis. All the samples were evaluated using the DIAGNOdent instrument.

After the tissue remnants had been removed and the teeth had been cleansed and polished, the study samples were sealed with acid resistant nail polish, leaving only a $2 \times 2 \mathrm{~mm}$ clearance on the buccal surfaces and subjected to demineralizationremineralization cycle to form initial enamel caries. In accord with the $\mathrm{pH}$ values of the solution used in the $\mathrm{pH}$ cycle, the time required to form the initial caries may vary $(14,15)$. Based on the existing literature, demineralization solution was prepared to contain 2.2 $\mathrm{mM} \mathrm{Ca}(\mathrm{NO} 3) 2,2.2 \mathrm{mM} \mathrm{KH} 2 \mathrm{PO} 4,0.1 \mathrm{ppm} \mathrm{NaF}$ and $50 \mathrm{mM}$ acetic acid. Likewise, remineralization solution was prepared to include $1.5 \mathrm{mM} \mathrm{CaCl} 2,0.9 \mathrm{mM} \mathrm{KH} 2 \mathrm{PO} 4,130$ $\mathrm{mM} \mathrm{KCl}, 20 \mathrm{mM}$ Hepes with $\mathrm{pH} 7(16,17)$. The teeth were subjected to $\mathrm{pH}$ cycle as demineralization for 6 hours and remineralization for 17 hours in an oven at $37^{\circ} \mathrm{C}$ for 9 consecutive days.

After the demineralisation-remineralization cycle, the teeth were kept in artificial saliva at $37^{\circ} \mathrm{C} \mathrm{pH} 7.0$ to simulate the oral environment for 30 minutes. Artificial saliva is primarily comprised of distilled water (99.6\%) and the following components: $0.08 \% \mathrm{NaCl}$, $0.12 \% \mathrm{KCl}, 0.01 \% \mathrm{MgCl} 2.6 \mathrm{H} 2 \mathrm{O}, 0.03 \% \mathrm{KH} 2 \mathrm{PO} 4,0.01 \%$ $\mathrm{CaCl} 2.2 \mathrm{H} 2 \mathrm{O}, 0.10 \%$ CMC-Na (sodium carboxymethyl cellulose).

DIAGNOdent (KaVo, Biberach, Germany), a laser fluorescence device, was used to evaluate demineralization and remineralization of the teeth. Both pre- and post-treatment measurements of the teeth were recorded with DIAGNOdent. 
For SEM and EDX analysis, the teeth were divided into buccolingual directions using a diamond disc (NTI, Germany). The teeth were dried in the oven for one day to prepare them for analysis and sealed with gold for 30 seconds using the Denton Vacuum Desk V. The samples were then evaluated with Hitachi VP-SEM SU1510.

\section{Statistical Analysis}

Statistical analysis of the data in our study was done using the SPSS (IBM®; 21.0 Windows, Chicago, USA) statistical program. Histological data; mean (M) and standard deviation (SD). Mann Whitney $U$ test was used to compare the data of the non-normal distributions of the two groups, and the Kruskal Wallis test was used to compare the two groups. The Bonferroni corrected Mann-Whitney $U$ test was performed in comparison to multiple groups. The differences between the groups were considered statistically significant at $p<0.05$.

\section{Results}

DIAGNOdent was used to evaluate the measurable changes on the enamel surface. The data were administered to LSD (Least Significant Difference) test and the paired samples t-tests before and after the treatment. The analysis results indicated no significant difference between the groups that displayed homogenous distribution prior to the treatment. The post-treatment intergroup comparison revealed a significant difference between the control group and treatment groups in favor of the treatment groups $(p<0.05)$. A significant difference was found between CPP-ACFP group and the fluoride group in favor of CPPACFP. No statistically significant difference was found among the other groups based on the paired comparison results (Table 1$)$. The pre- and posttreatment evaluation results indicated that all groups except the control group displayed statistically significant difference in terms of treatment $(p<0.05)$ (Table 2).

Table 1. Post-treatment evaluation of DIAGNOdent between the groups

\begin{tabular}{|c|c|c|c|c|}
\hline (I) Groups & (J) Groups & Mean Difference (I-J) & Std. Error & Sig*. \\
\hline \multirow[t]{4}{*}{ Control } & Fluorine & $3,85000^{*}$ & 1,21761 & ,018 \\
\hline & CPP-ACP & $5,85000^{*}$ & 1,21761 & ,000 \\
\hline & CPP-ACFP & $7,40000^{*}$ & 1,21761 & ,000 \\
\hline & $\mathrm{TCP}$ & $6,10000^{*}$ & 1,21761 & ,000 \\
\hline \multirow[t]{3}{*}{ Fluorine } & CPP-ACP & 2,00000 & 1,21761 & ,474 \\
\hline & CPP-ACFP & $3,55000^{*}$ & 1,21761 & ,035 \\
\hline & TCP & 2,25000 & 1,21761 &, 353 \\
\hline \multirow[t]{2}{*}{ CPP-ACP } & CPP-ACFP & 1,55000 & 1,21761 & ,708 \\
\hline & TCP & ,25000 & 1,21761 & 1,000 \\
\hline TCP & CPP-ACFP & 1,30000 & 1,21761 & ,823 \\
\hline
\end{tabular}

Table 2. Statistical evaluation pre- and post-treatment

\begin{tabular}{lcccccc} 
Groups & Treatment & Mean & N & Std. Deviation & Correlation & Sig.* \\
\hline Fluorine & Pre-treatment & 14,9500 & 20 & 3,57587 &, 969 &, 000 \\
& Post-treatment & 12,9000 & 20 & 3,40124 &, 000 \\
CPP-ACP & Pre-treatment & 16,2500 & 20 & 3,85084 &, 901 &, 000 \\
& Post-treatment & 10,9000 & 20 & 4,01182 &, 804 &, 000 \\
CPP-ACFP & Pre-treatment & 14,9500 & 20 & 3,79022 &, 755 &, 000 \\
& Post-treatment & 9,3500 & 20 & 2,88873 & 3,05045 & \\
TCP & Pre-treatment & 14,6000 & 20 & 3,43995 & &
\end{tabular}


The analysis of SEM images demonstrated that the application of different treatment agents to enamel surfaces with initial enamel caries lesion triggered different morphological changes after remineralization. Namely, initial caries were recorded only in the control group. Furthermore, when SEM images taken from demineralized areas were examined, irregularities in enamel prisms, small cracks on the surface and dilations of prism diameters were observed (Figure 1a, b). When SEM images of $\mathrm{NaF}$ varnish were applied a porous structure, calcified sediments and cracks were observed on the surface (Figure 2a, b). When they were examined in the CPPACP group, it was observed that a long crack on the surface and calcified deposits were accumulated on porous structures (Figure $3 a, b$ ).

When they were examined in the CPP-ACFP group, calcified sediments and very small amount of porous tissue were observed in a large area (Figure $4 a, b$ ).
When they were examined in the TCP group, calcified deposits were observed on the tooth surface (Figure 5a, b).

\section{EDX Analysis Results:}

EDX analysis spectra are presented in Figure 6 for the control group, Figure 7 for the fluoride varnish group, Figure 8 for the CPP-ACP group, Figure 9 for the CPP-ACFP group and Figure 10 for the TCP group.

The statistical results of the EDX analysis to compare the average atomic $\mathrm{Ca} / \mathrm{P}$ ratios between the groups through revealed that the $\mathrm{Ca} / \mathrm{P}$ ratio of CPPACFP group was significantly different from all groups except the fluoride group $(p<0.05)$ (Table 3$)$.

Table 3. Evaluation of EDX Ca / P values with LSD analysis

\begin{tabular}{|c|c|c|c|c|c|}
\hline Dependent Variable & (I) Sample & $\begin{array}{l}\text { (J) Sample } \\
\text { treatment }\end{array}$ & Mean Difference (I-J) & Std. Error & Sig. * \\
\hline \multirow{10}{*}{$\mathrm{Ca} / \mathrm{P}$} & \multirow{4}{*}{ Control } & Fluorine & ,15700 & ,10751 & , 151 \\
\hline & & CPP-ACP & ,04200 & ,10751 & 698 \\
\hline & & CPP-ACFP &, $34400^{*}$ & ,10751 &, 003 \\
\hline & & TCP & ,12300 & ,10751 & ,259 \\
\hline & \multirow{3}{*}{ Fluorine } & CPP-ACP & , 11500 & ,10751 & ,290 \\
\hline & & CPP-ACFP & , 18700 & , 10751 & 089 \\
\hline & & TCP & ,03400 & ,10751 & ,753 \\
\hline & \multirow{2}{*}{ CPP-ACP } & CPP-ACFP & ,30200* & ,10751 & ,007 \\
\hline & & TCP & ,08100 & , 10751 & ,455 \\
\hline & CPP- ACFP & $\mathrm{TCP}$ &, $22100^{*}$ & ,10751 & ,046 \\
\hline
\end{tabular}

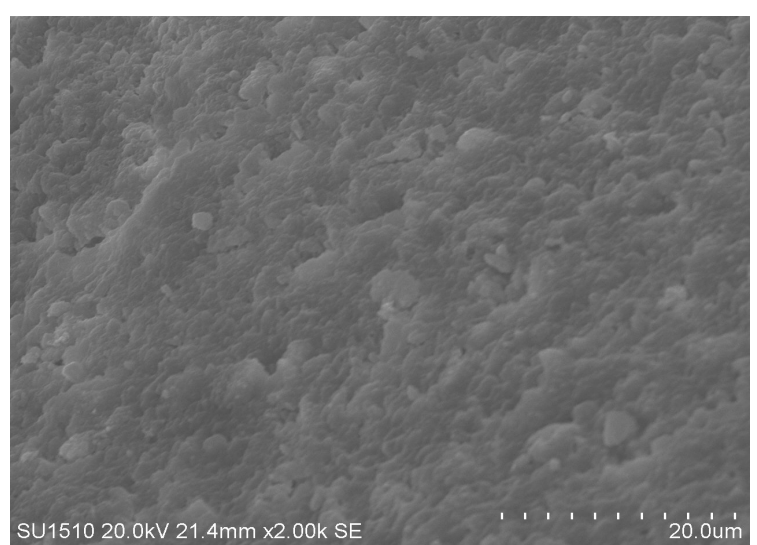

Figure 1. SEM image of the control group (2000x magnification)

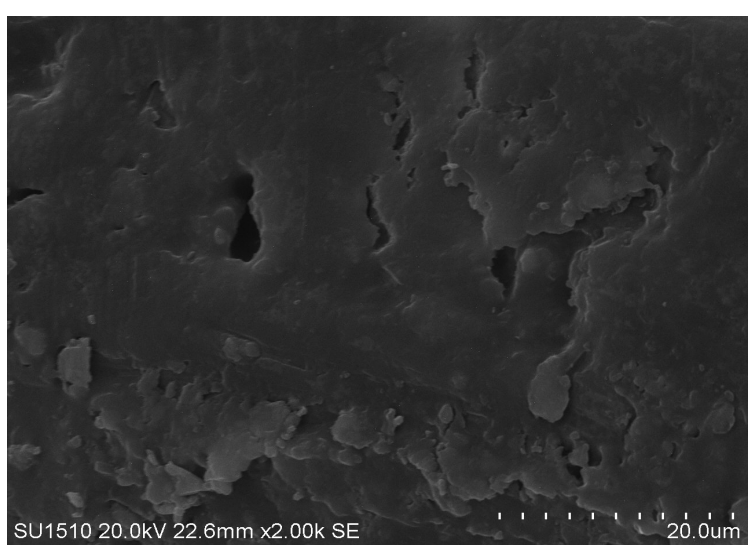

Figure 2. SEM image of $\mathrm{NaF}$ varnish group (2000x magnification) 


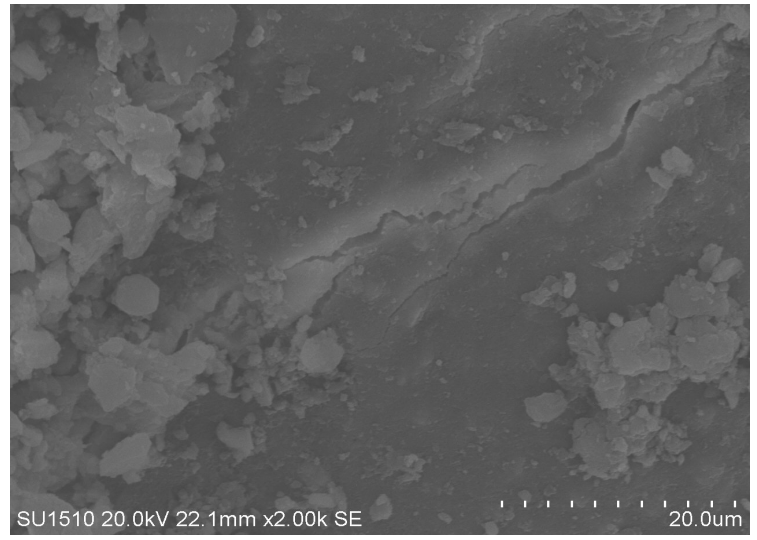

Figure 3. SEM image of CPP-ACP group (2000x magnification)

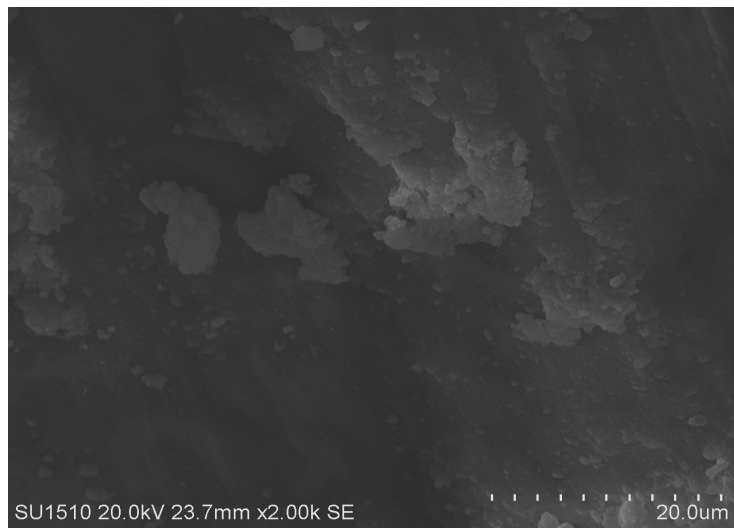

Figure 4. SEM image of CPP-ACFP group (2000x magnification)

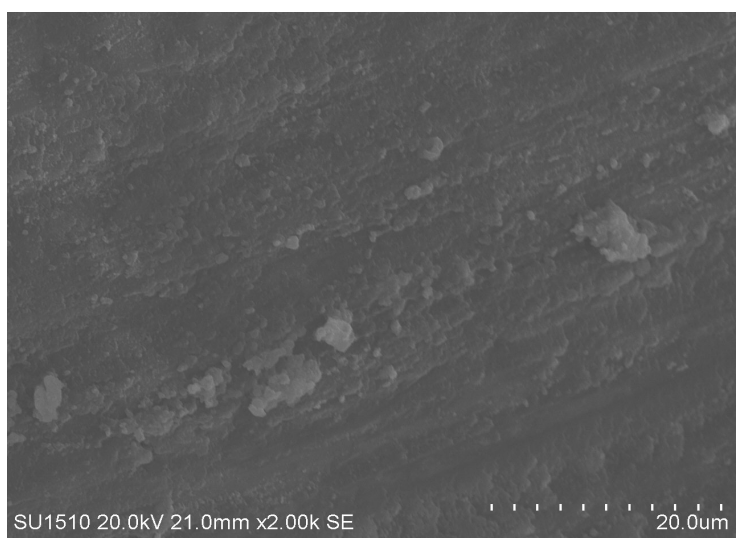

Figure 5. SEM image of TCP group (2000x magnification)

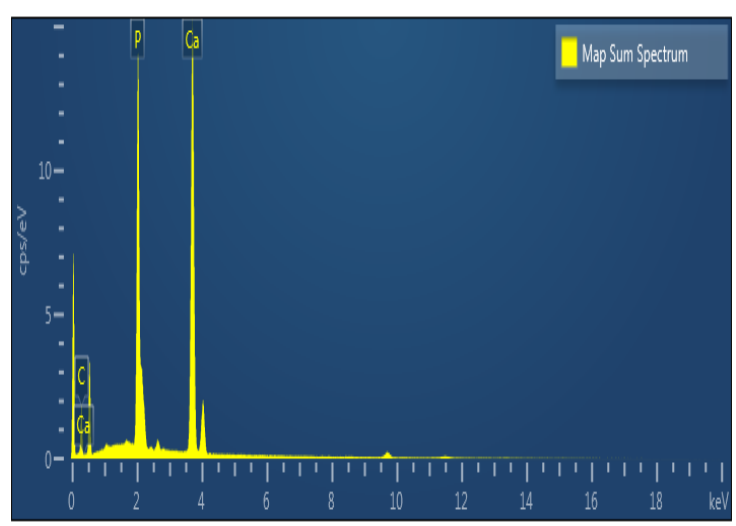

Figure 6. Control group EDX field spectrum

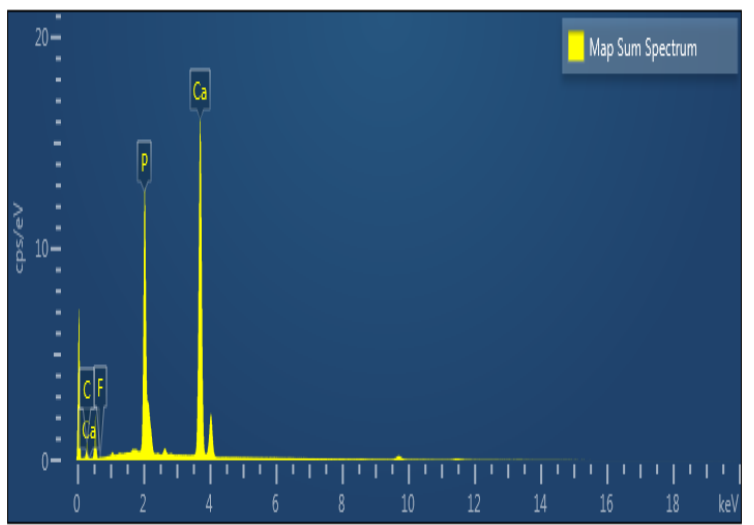

Figure 7. Fluorine varnish group EDX field spectrum

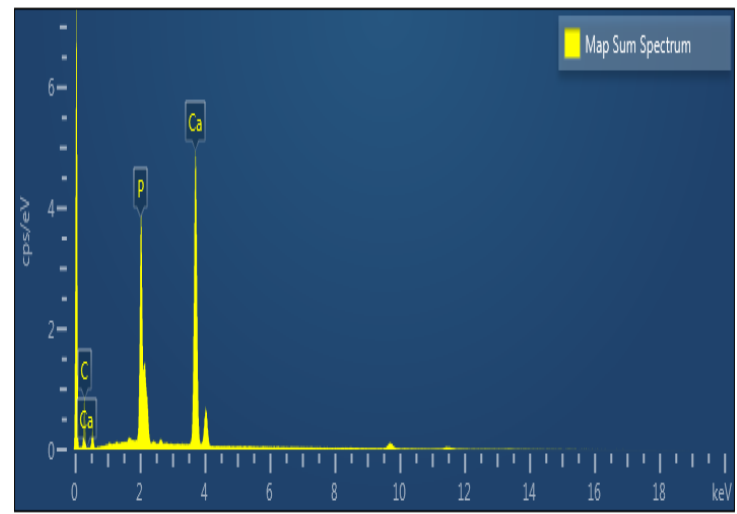

Figure 8. CPP-ACP group EDX field spectrum

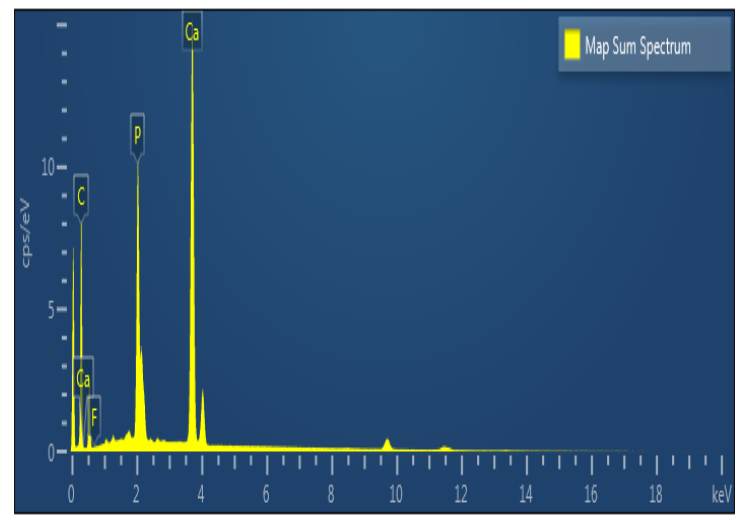

Figure 9. CPP-ACFP group EDX field spectrum

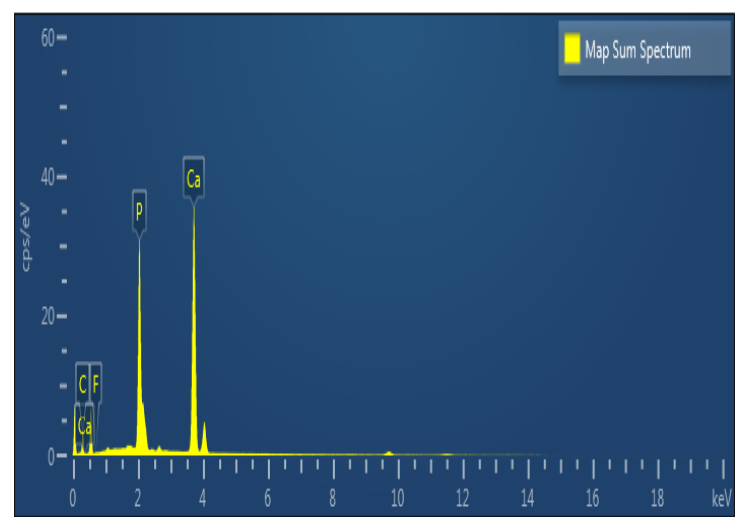

Figure 10. TCP group EDX field spectrum

IDR - Volume 9, Number 3, 2019 


\section{Discussion}

The current study has shown that the demineralization-remineralization cycle affects the mineral levels of the teeth. The EDX analysis, used to evaluate the mineral levels and the ratio of minerals to each other, was utilized to observe the quantity of minerals in the teeth with initial caries and remineralized. Our findings somehow overlap with Kamath et al. who previously reported that EDX analysis results were found highly significant in group evaluations in an in vitro study (18). However, on the contrary to the findings of Kamath et al (18), our study showed that the $\mathrm{Ca} / \mathrm{P}$ ratio of CPP-ACFP group was found significantly different from those measured in the other groups except the fluoride group $(p<0.05)$.

Conducted on the post-treatment evaluation of the remineralization effect on teeth surface through DIAGNODENT, this study revealed a statistically significant difference between the control group and the treatment groups in favour of the latter $(p<0.05)$. In addition, such difference was found between the CPP-ACFP and the flourine group in favour of the former. These findings are in line with Pai et al. (10) and Jayarayan et al. while they contradict with Patil et al. (11).

\section{Conclusions}

The current study has concluded that fluoride varnish application proved effective in remineralization of artificial caries in primary tooth enamel, that TCP varnish had similar effects to fluoride varnish in remineralization, and that CPP-ACFP cream provides a higher remineralizing effect in comparison to the other remineralizing agents.

This study was limited to the investigation of the effects of remineralization agents through SEM images and EDX analysis. Hence, further studies could explore the effects of remineralization via other techniques such as FTIR, ICP AES, and SMH.

Ethical Approval: Ethics committee approval was received for this study from Dicle University (No:2017/7).

Peer-review: Externally peer-reviewed.

Author Contributions: Conception- E.T., I.R.T.; Design- E.T., I.R.T.; Supervision- M.C.Y.; Materials - E.T., I.R.T.; Data Collection and/or Processing - I.R.T.; Analysis and/or Interpretation- E.T..; Literature Review- E.T., I.R.T.; Writer- E.T.; Critical Review- I.R.T.

Conflict of Interest: No conflict of interest was declared by the authors.

Financial Disclosure: The authors declared that this study has received no financial support.

\section{References}

1. Clarkson JJ, McLoughlin J. Role of fluoride in oral health promotion. Int Dent J. 2000;50(3):119-28. (Crossref)

2. Keskin G. Kazein Fosfopeptit Amorf Kalsiyum Fosfat Ve Amelogeninin Mine Remineralizasyonuna Etkisi. İnönü Üniversitesi; 2014.

3. Çetin B, Avșar A, Ulusoy AT. Kazein içerikli besinler ve dental ürünler. Atatürk Üniversitesi Diș Hekim Fakültesi Derg. 2011;(4):24-31.

4. Rechmann P, Bekmezian S, Rechmann BM, Chaffee BW, Featherstone JD. MI Varnish and MI Paste Plus in a caries prevention and remineralization study: a randomized controlled trial. Clin Oral Investig. 2018;22(6):2229-2239. (Crossref)

5. Reynolds EC. Anticariogenic complexes of amorphous calcium phosphate stabilized by casein phosphopeptides: A review. Spec Care Dent. 1998;18(1):8-16. (Crossref)

6. Karlinsey RL, Mackey AC, Walker ER, Frederick KE. Preparation, characterization and in vitro efficacy of an acid-modified BTCP material for dental hard-tissue remineralization. Acta Biomater. 2010;6(3):969-78. (Crossref)

7. Hegde MN, Moany A. Remineralization of enamel subsurface lesions with casein phosphopeptide-amorphous calcium phosphate: A quantitative energy dispersive $\mathrm{X}$-ray analysis using scanning electron microscopy: An in vitro study. J Conserv Dent. 2012;15(1):61-7.

8. Dilber E, Malkoc MA, Ozturk AN, Ozturk F. Effect of various laser irradiations on the mineral content of dentin. Eur J Dent. 2013;7(1):74-80.

9. Memiş HB. Teobromin, mine matriks protein türevi, kazein fosfopeptit amorf kalsiyum fosfat ve deniz tuzunun ortodontik braketler etrafındaki minenin remineralizasyonuna etkisinin in vitro olarak incelenmesi. 2018.

10. Pai D, Bhat S, Taranath A, Sargod S, Pai V. Use of Laser fluorescence and Scanning Electron Microscope to Evaluate Remineralization of Incipient Enamel Lesions Remineralized by Topical Application of Casein Phospho Peptide Amorphous Calcium Phosphate (CPP-ACP) Containing Cream. J Clin Pediatr Dent. 2008;32(3):201-6. (Crossref)

11. Jayarajan J, Janardhanam $P$, Jayakumar $P$, Deepika. Efficacy of CPP-ACP and CPP-ACPF on enamel remineralization - an in vitro study using scanning electron microscope and DIAGNOdent. Indian J Dent Res. 2011;22(1):77-82. (Crossref)

12. Bhat S, Hegde K, Habibullah M, Bernhardt V. Incipient Enamel Lesions Remineralization using Casein Phosphopeptide Amorphous Calcium Phosphate Cream with and without Fluoride: A Laser Fluorescence Study. J Clin Pediatr Dent. 2012;36(4):253-355. (Crossref)

13. Patil N, Choudhari S, Kulkarni S, Joshi SR. Comparative evaluation of remineralizing potential of three agents on artificially demineralized human enamel: An in vitro study. J Conserv Dent. 2013;16(2):116-20. (Crossref)

14. Allama Prabhu, BG, Sakeenabhi B, Prashanth GM, Subramaniam $R$, Ragher M. Effect of fluoride varnish and dentifrices and its combination on deciduous enamel demineralization: An In vitro study. J Pharm Bioallied Sci. 2017;9(1):112-6. (Crossref)

15. Shetty S, Hegde M, Bopanna T. Enamel remineralization assessment after treatment with three different remineralizing agents using surface microhardness: An in vitro study. J Conserv Dent. 2014;17(1):49. (Crossref)

16. Zhou C, Zhang D, Bai Y, Li S. Casein phosphopeptide-amorphous calcium phosphate remineralization of primary teeth early enamel lesions. J Dent. 2014;42(1):21-9. (Crossref) 
17. ten Cate JM, Duijsters PPE. Alternating Demineralization and Remineralization of Artificial Enamel Lesions. Caries Res. 1982;16(3):201-10. (Crossref)

18. Kamath P, Nayak R, Kamath SU, Pai D. A comparative evaluation of the remineralization potential of three commercially available remineralizing agents on white spot lesions in primary teeth: An in vitro study. J Indian Soc Pedod Prev Dent [Internet]. 2017 [cited 2018 Sep 20];35(3):229-37. (Crossref) 